\title{
Enhancing Power Grid Resilience through an IEC61850-based EV-assisted Load Restoration
}

\author{
Pouya Jamborsalamati, Student Member, IEEE, M. Jahangir Hossain, Senior Member, IEEE, Seyedfoad \\ Taghizadeh, Student Member, IEEE, Georgios Konstantinou, Senior Member, IEEE, Moein Manbachi, Graduate \\ Student Member, IEEE, and Payman Dehghanian, Member, IEEE,
}

\begin{abstract}
Contrary to reliability analysis in power systems with the main mission on safely and securely withstanding credible contingencies in day-to-day operations, resilience assessments are centered on high-impact low probability (HILP) events in the grid. This paper proposes an autonomous load restoration architecture founded on IEC 61850-8-1 GOOSE communication protocol to engender an enhanced feeder-level resilience in active power distribution grids. Different from the past research on outage management solutions, most of which (a) are not resilience-driven, (b) are reactive solutions to local single-fault events, and (c) do not address both network built-in flexibilities and flexible resources, the proposed solution harnesses (a) the imported power and flexibility from the neighboring networks, (b) Distributed Energy Resources (DERs), and (c) vehicle to grid (V2G) capacity of Electric Vehicles (EVs) aggregations to enhance the feeder-level resourcefulness for agile response and recovery. Through real-time self-reconfiguration strategies, the suggested solution is capable of coping both single and subsequent outage events, and will engender a heightened resilience before and during the contingency period. Moreover, a resilience evaluation framework, which quantifies the contribution of all resources involved in service restoration, is developed. Real-time performance of the designed architecture is evaluated on a realworld power distribution grid using a real-time Hardware-in-theLoop (HIL) platform. Numerical case studies through a number of diverse scenarios demonstrate the efficacy of the proposed restoration solution in practicing an enhanced resilience in power distribution systems in response to HILP scenarios.
\end{abstract}

Index Terms-Smart Distribution Grids, Resilience, Electric Vehicle (EV), IEC 61850, Hardware-in-the-Loop Platform.

\section{NOMENCLATURE}

$R C C_{i, t} \quad$ Reserve Current Capacity of the $i^{t h}$ feeder at time $t$.

FTC $C_{i} \quad$ Feeding Transformer Capacity of the $i^{\text {th }}$ feeder.

$V_{s, i}^{T R} \quad$ Rated voltage level at the secondary side of the transformer in the the $i^{t h}$ feeder.

P. Jamborsalamati, M. J. Hossain, and S. Taghizadeh are with the School of Engineering, Macquarie University, Sydney, NSW 2109, Australia (email:pouya.jamborsalamati@hdr.mq.edu.au, jahangir.hossain@mq.edu.au, s.t.taghizadeh@ieee.org).

G. Konstantinou is with the School of Electrical Engineering and Telecommunications, University of New South Wales, Sydney, NSW 2052, Australia (e-mail: g.konstantinou@unsw.edu.au).

M. Manbachi is with the Department of Electrical and Computer Engineering, University of British Columbia, Vancouver, BC V6T 1Z4, Canada (e-mail: moeinmanbachi@ece.ubc.ca)

P. Dehghanian is with the Department of Electrical and Computer Engineering, The George Washington University, Washington, DC 20052, USA (email: payman@gwu.edu).
$I_{s, i, t}^{T R} \quad$ Current flow at the secondary side of the transformer in the $i^{t h}$ feeder at time $t$.

$P_{b, t}, P_{b, t}^{0} \quad$ Active power at each bus at time $t$ and its

$Q_{b, t}, Q_{b, t}^{0}$ initial value.

$V_{b, t}, V_{b, t}^{0}$ Reactive power at each bus at time $t$ and its initial value.

$Z_{p}, I_{p}, P_{p} \quad$ value.

$Z_{q}, I_{q}, P_{q} \quad$ Reactive ZIP load coefficients.

$P_{D E R, t} \quad$ Active power injected by DER unit at time interval $t$.

$P_{i}^{G 2 V} \quad$ Average charging power of the $i^{t h} \mathrm{EV}$.

$P_{i}^{V} 2 G$

$p_{i, t}^{C}, p_{i, t}^{D}$ Average discharging power of the $i^{t h} \mathrm{EV}$.

Instantaneous charging and discharging power of the $i^{\text {th }} \mathrm{EV}$.

$P_{V 2 G}^{T o t} \quad$ Total injected power by each EVAU during the restoration period.

$E_{t}^{E V A U_{i}} \quad$ Total available energy in the $i^{t h}$ EVAU at time interval $t$.

$E_{i}^{\text {min }} \quad$ Minimum energy required for the $i^{t h} \mathrm{EV}$ battery serving its mobility.

$E_{i}^{0} \quad$ Initial energy in the $i^{\text {th }} \mathrm{EV}$ battery determined by its initial State of Charge (SoC).

$I_{\text {demand }}^{\text {Tot }} \quad$ Total current of the restorable demand.

$\begin{array}{ll}T \text { Tot } & \text { Total current injected by DERs during the }\end{array}$ restoration period.

$I_{V 2 G}^{T o t} \quad$ Total current injected by EVs during the restoration.

$\Delta t_{i}^{G 2 V} \quad$ Charging time interval of the $i^{t h} \mathrm{EV}$.

$\Delta t_{i}^{V 2 G}$

$\Delta t_{i}$

$S$

$n_{i}$

$I B^{T}$ ot

$E B^{T}$ ot

Discharging time interval of the $i^{t h} \mathrm{EV}$.

Minutes of interruption related to the $i^{\text {th }}$ restoration step.

Total number of steps in a restoration plan.

Number of customers involved in the $i^{\text {th }}$ restoration step.

Total current injected by internal backups for restoration.

TTR Total time to restoration in a restoration plan. $\eta_{i}^{C}, \eta_{i}^{D} \quad$ Charging and discharging efficiency of the $i^{t h}$

$\lambda_{i, t}^{C}, \lambda_{i, t}^{D}$ $\mathrm{EV}$ in the fleet.

Binary variables indicating charging and discharging status of the $i^{t h} \mathrm{EV}$ battery. 
$\gamma_{t} \quad$ Time-variant number of ready-to-dispatch EVs in the fleet.

$\alpha \quad$ Contribution factor of the RCC in restoration. $\beta \quad$ Contribution factor of the DERs in restoration. $\zeta \quad$ Contribution factor of the EVs in restoration.

\section{INTRODUCTION}

Enhancing the ability of power grids to avert possible event-driven damages, tolerate accidents within the system, and swiftly bounce back to a normal operating condition following a disruption can manifest a well-resilient power system [1]. High Impact Low Probability (HILP) events, such as natural disasters and cyber attacks, can result in remarkable technical and economic losses in the entire energy landscape. Therefore, it is of great importance for power utilities to increase awareness against HILP events and to reduce the outage of the end customers by effective strategies that best harness the integration of modern grid resources and flexible services before, during, and following a HILP disaster [2], [3].

Research on power distribution network resilience and the corresponding solutions could be categorized by single-node improvements or collective (feeder) level enhancements [4]. In another classification, actions for escalation of grid-scale resilience could be taken at three different timescales [5]:

1) Pre-event System Planning: which includes preventive actions before the event happens, such as grid hardening and reinforcement of the infrastructure by installation of new devices. These actions increase infrastructural resilience [6].

2) System Operation During the Event: where corrective actions are triggered to avoid the system blackout. Corrective actions aim to stop a possible cascade scenario through swift response and fast isolation of the predicted fault tree in the network connectivity map [2].

3) Post-Event Service Restoration (SR): which points out to the system operational resilience, where grid services, including traditional and modernized network flexible resources, are deployed for time-critical restoration of the healthy segments of the affected feeder. [7], [8].

In [7], [9]-[15], automated feeder reconfiguration schemes for load restoration are presented and the impact of Distributed Energy Resources (DERs) on reliability of power systems is investigated. In these studies, microgrids are employed to contribute to the restoration of critical loads by prioritizing the restorable demand. However, SRs demonstrated in the aforementioned articles are aimed to heal the credible contingencies and are not focused to the extreme HILP incidents. Agentbased frameworks for SR are designed and implemented for active distribution grids in [16]-[19]. Although DER agents and storage components are proposed within the multi-agent outage management systems, the contribution of other modernized grid services, such as Electric Vehicles (EVs), for resilience is not properly addressed, where EV aggregators could be an additional agent in a multi-agent SR scheme. In [20], [21], restoration algorithms in passive distribution grids with unidirectional current flows are suggested which rely solely on the extra capacity available from the adjacent feeders and, therefore, comes at a higher cost compared to using the local generations. Effective utilization of the internal resources, located in healthy segments of a faulty feeder, for service restoration is not studied in most of the past literature.

Higher penetration of EVs in smart grids along with largescale utilization of multi-functional EV chargers in the near future enables new potentials to be harnessed in service restoration [22], [23]. References [23]-[30] have investigated integration of EVs in distribution grids and the potential ancillary services such as Volt-VAR optimization and outage management by Vehicle-to-Grid (V2G) services. Nevertheless, these studies (a) do not consider and coordinate both network built-in flexibilities and other flexible resources, (b) are not primarily designed for resilience services to be able to capture the subsequent events and sequential restoration steps, and (c) are limited to local single-fault events.

Different from the past research, the proposed SR solution focuses on HILP events (e.g., extreme weather conditions) and harnesses network flexibilities, including external and internal resources with quantified contribution factors. Furthermore, real-time evaluation of the designed SR, implemented with real communications, is presented by online evaluation of the proposed collective-level resilience metrics. The main advantage of the proposed SR solution is to consider both traditional and modernized grid services in all subsequent events and sequential restoration steps in response to HILP events. Contributions of this paper are summarized below:

- The proposed SR scheme in this paper offers provisions to effectively respond to disastrous events with subsequent impacts on the grid (multiple faults).

- In addition to the imported flexibility from external and adjacent networks, the proposed autonomous SR in this paper dispatches all modern resources including DERs, and especially the aggregated non-faulty V2G capacity in a faulty feeder as a new SR resource. The developed solution continues dispatching these modern SR services even during the successive events, which in turn, relaxes the stress on the external resources and enhances feederlevel resourcefulness and resilience.

- A new feeder-level resilience metric for load restoration is proposed which allows quantifying the performance of the solutions and the impacts on the grid resilience.

- The real-time performance and scalability of the proposed SR approach are verified on a real-world Medium Voltage (MV) distribution grid, managed by A2A Unareti [21] in a practical setting. This includes Hardware-in-the-Loop (HIL) simulations using specialized output boards of Real Time Digital Simulator (RTDS), which are capable of standardized publisher/subscriber IEC 61850-8-1 GOOSE communication [31].

The rest of the paper presents the designed operational units for the proposed SR solution in Section II, work-flow diagrams and SR messaging platform in Section III, HIL testing platform in Section IV, and realistic case scenarios and detailed analysis of the results in Section V. 


\section{The Proposed Hierarchical Self-Healing} System: Architecture, Components, And Models

The proposed self-reconfiguration system in this paper focuses on radial distribution grids in the presence of DER units and EVs. The system architectural overview along with functional units are displayed in Fig. 1 and described below:

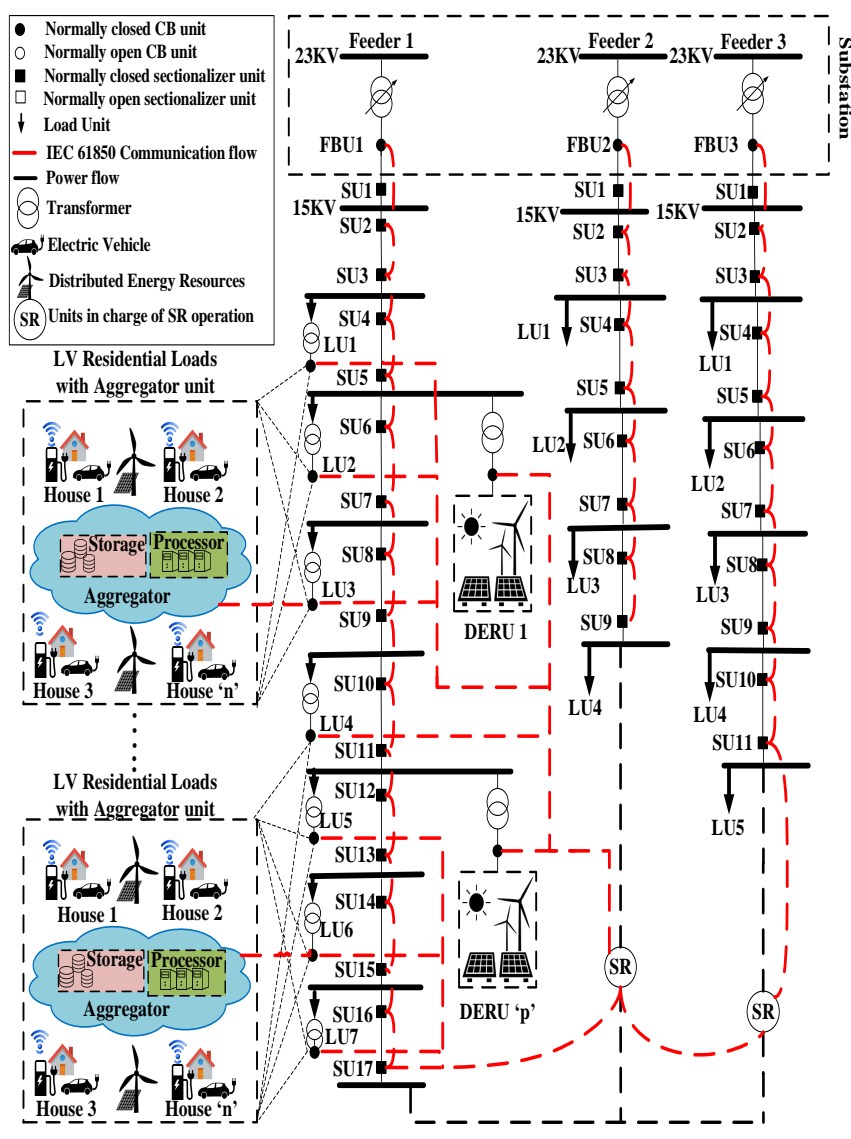

Fig. 1. Generic view of the proposed hierarchical architecture.

1) Feeder Breaker Units (FBUs): FBUs are located in the substations and include re-closing overcurrent relays, current transformers, and computational modules to frequently calculate and report the Reserve Current Capacity $(R C C)$ of the feeder. In $R C C$ calculations, the Feeding Transformer Capacity $(F T C)$ and the current flow in the secondary side of the feeder transformer are characterized as follows:

$$
R C C_{i, t}=\left(F T C_{i} / V_{s, i}^{T R}\right)-I_{s, i, t}^{T R}
$$

2) Sectionalizer Units (SUs): SUs are responsible to detect overcurrent conditions, report it to the relevant units, and operate remotely to isolate a detected fault. Due to the bidirectional current flows in active radial distribution feeders, SUs typically consist of directional overcurrent relays and sectionalizing switches that are located at each terminal of the feeders in a double-ended protection fashion.

3) Load Units (LUs): LUs are connected to each busbar covering the smart residential zone of the busbar. Smart residential loads include Electric Vehicles (EVs) capable of charging/discharging remotely. ZIP load modeling, presented in [8], is adopted in (2) to characterize the load active and reactive power (with/without EVs):

$$
\begin{aligned}
& P_{b, t}=P_{b, t}^{0}\left(Z_{p}\left(V_{b, t} / V_{b, t}^{0}\right)^{2}+I_{p}\left(V_{b, t} / V_{b, t}^{0}\right)+P_{p}\right) \\
& Q_{b, t}=Q_{b, t}^{0}\left(Z_{q}\left(V_{b, t} / V_{b, t}^{0}\right)^{2}+I_{q}\left(V_{b, t} / V_{b, t}^{0}\right)+P_{q}\right)
\end{aligned}
$$

where $\left(P_{b, t}, P_{b, t}^{0}\right)$ and $\left(Q_{b, t}, Q_{b, t}^{0}\right)$ represent the active and reactive power and their initial values for each busbar at each time interval $t .\left(Z_{p}, I_{p}, P_{p}\right)$ and $\left(Z_{q}, I_{q}, P_{q}\right)$ are the active and reactive ZIP load coefficients respectively. LUs include current transformers and computational modules to calculate and report the total current demand of their corresponding medium-voltage zones.

4) DER Units (DERUs): DERUs are equipped with breakers that operate remotely, upon reception of certain published messages in the network, to isolate the DER in case of a fault or to bring the DER unit back into the system operation during the SR process. Furthermore, DERUs publish their breakers current flows frequently and check the constraints on the active power injection of the DER units to the connected busbar as indicated in (4), where $P_{D E R, t}$ is the active power injected by the DER unit to the connected busbar:

$$
P_{D E R, t}^{\min } \leqslant P_{D E R, t} \leqslant P_{D E R, t}^{\max }
$$

5) EV Aggregator Units (EVAUs): EVAUs are entities responsible for aggregation of EVs charging/discharging profiles. These units communicate with other intelligent devices in the network to remotely control the EV chargers in their zone. Under fault scenarios, EVs are disconnected and those willing to participate in SR process would be effectively dispatched to inject power to the grid, once they receive the dispatch command from the EVAUs. The aggregated EV load profiles are reflected in the ZIP load models by changing the corresponding coefficients for aggregation of EVs. Among the different operational modes for EV chargers, the most common EV operating scenario for inverters is adopted here [32], where $P>0, Q=0$ are set during charging and $P<0, Q=0$ are enforced during discharging operational modes. This reflects the fact that the EV fleet at each charging period consumes active power from the grid, while during the discharging (V2G) time interval, EVs which are plugged in and selected by the EVAUs would start injecting active power to the grid. It must be noted that EVAUs always ensure that there is enough energy remaining in each EV after the V2G time interval to meet the demanded mobility, which is the EVs primary function. The available energy by each EVAU and its corresponding constraints are formulated as follows:

$$
E_{t}^{E V A U_{j}}=\sum_{i}^{\gamma_{t}}\left(\left(E_{i}^{0}+P_{i}^{G 2 V} \times \Delta t_{i}^{G 2 V}\right)-P_{i}^{V 2 G} \times \Delta t_{i}^{V 2 G}\right)
$$

$$
\begin{aligned}
& P_{i}^{G 2 V}=\left(\frac{1}{\Delta t_{i}^{G 2 V}} \int_{0}^{\Delta t_{i}^{G 2 V}}\left(p_{i, t}^{C} \times \lambda_{i, t}^{C}\right) d t\right) \times \eta_{i}^{C} \\
& P_{i}^{V 2 G}=\left(\frac{1}{\Delta t_{i}^{V 2 G}} \int_{0}^{\Delta t_{i}^{V 2 G}}\left(p_{i, t}^{D} \times \lambda_{i, t}^{D}\right) d t\right) \times \eta_{i}^{D}
\end{aligned}
$$$$
\lambda_{i, t}^{C}+\lambda_{i, t}^{D}=1, \quad \lambda_{i, t}^{C}, \lambda_{i, t}^{D} \in\{0,1\}
$$ 


$$
\begin{gathered}
P_{V 2 G}^{T o t}=\sum_{i}^{\gamma_{t}} P_{i}^{V 2 G} \\
E_{i}^{m i n} \leqslant\left(E_{i}^{0}+P_{i}^{G 2 V} \times \Delta t_{i}^{G 2 V}\right)-P_{i}^{V 2 G} \times \Delta t_{i}^{V 2 G} \\
0 \leqslant p_{i, t}^{C} \leqslant p_{i}^{C, \max } \times \lambda_{i, t}^{C} \\
0 \leqslant p_{i, t}^{D} \leqslant p_{i}^{D, \max } \times \lambda_{i, t}^{D}
\end{gathered}
$$

Eq. (5) expresses the total available energy in the $j^{t} h$ EVAU at time $t$ denoted by $\left(E_{t}^{E V A U_{j}}\right)$ and is assessed by summation over the time-variant number of EVs in the fleet which are plugged in and ready to dispatch $\left(\gamma_{t}\right) . E_{t}^{E V A U_{j}}$ is periodically published by each EVAU and subscribed by the units in charge of making decision for restoration in case of a fault or other prevailing conditions. The first term in (5) represents the energy in a single EV in the fleet after a charging interval $\left(\Delta t_{i}^{G 2 V}\right)$ where $E_{i}^{0}$ is the initial energy in each EV battery determined by its initial State of Charge (SoC), and $P_{i}^{G 2 V}$ is the average charging power of each EV. The second term in (5) represents the energy injected to the grid over a discharging interval $\left(\Delta t_{i}^{V 2 G}\right)$, where $P_{i}^{V 2 G}$ is the average discharging power of each EV. Eqs. (6) and (7) reflect the $P_{i}^{G 2 V}$ and $P_{i}^{V 2 G}$ assessment over the charging and discharging intervals, where $\eta_{i}^{C}$ and $\eta_{i}^{D}$ are the charging and discharging efficiency of each EV, respectively; $\lambda_{i, t}^{C}$ and $\lambda_{i, t}^{D}$ in (8) are binary variables to avoid charging and discharging at the same time. The total injected power by each EVAU after a discharging interval $\left(P_{V 2 G}^{T o t}\right)$ to be used during the SR process is assessed in (9). Constraint (10) limits the discharging energy at each EV to ensure there is sufficient energy after the V2G interval for its mobility; $E_{i}^{\text {min }}$ is the minimum SoC of the EVs required for motion. Constraints on charging and discharging power of each EV are enforced in (9) and (10), where $p_{i, t}^{C}$ and $p_{i, t}^{D}$ are instantaneous charging and discharging power, respectively.

6) SR Units (SRUs): SRUs play a key role in the SR process. They consist of normally-open circuit breakers which connect two radial feeders. SRUs are intelligent units that receive information (including measurements and statuses) from all other units, run the SR algorithm, and publish the results (re-configuration commands) to be subscribed and actuated by the corresponding units in the network. The SR algorithm runs in SRUs to restore the non-faulty loads of a feeder by utilizing all the available resources in the post-event interval. SRUs check the following criterion to make decisions on closing the Tie-breakers in their unit:

$$
I_{\text {demand }}^{\text {Tot }} \leqslant(\alpha \times R C C)+\left(\beta \times I_{D E R}^{T o t}\right)+\left(\zeta \times I_{V 2 G}^{T o t}\right)
$$

where $I_{\text {demand }}^{\text {Tot }}$ is the current representing the non-faulty loads to be restored; $R C C$ is the reserve current capacity of the feeder that would be connected to the faulty feeder by closing the Tie-breaker in the SRU; $I_{D E R}^{T o t}$ is the current that could be injected by the DER units located in the nonfaulty section of the feeder and is assessed via $P_{D E R}$ received from DERUs; and $I_{V 2 G}^{T o t}$ is the potential current that could be injected by the EVs located in the non-faulty zone and is assessed by $P_{V 2 G}^{T o t}$ received from EVAUs. $\alpha, \beta$, and $\zeta$ are auxiliary parameters designed to ensure that the decision on employing various resources (i.e., RCC, DER, and EVs) for SR do not heavily rely on EVs and DERs, where much higher capacity uncertainty can unfold than from resources in the adjacent feeders. Note that the main SR resource is the assisting capacity from the adjacent feeders, and DERUs and EVAUs are employed as the auxiliary resources for SR. These parameters could be tuned in such a way that even in the worst case scenario, where there is no contribution from DERUs and EVAUs, the SR algorithm converges and only certain pre-determined overload limits are violated. This could be achieved by checking condition (13), where $\beta$ and $\zeta$ are set to zero.

\section{Proposed EV-Assisted LoAd Restoration}

The proposed units are deployed as finite-state machines and can switch between operational modes which are triggered upon reception of the external messages. The operational states for each unit are displayed in Fig. 2 and the messages exchanged among the units are tabulated in Table I. There are two main assumptions in this paper: (i) radial operation of the feeder is always ensured, and (ii) protection devices are fast and fully reliable. All units operate in "Normal State" when there is no event in the grid. Measurements, including load current demands, available $R C C, I_{D E R}$, and $P_{V 2 G}^{T o t}$, are continuously exchanged between the units. When an event occurs, FBU and DERUs are the first units to react. DERUs sense an overcurrent and, hence, transit into a "Fault State" by opening the DER breakers, and wait to receive a "Reconnect" message from the SRUs to contribute to the SR process. In such circumstances, FBU switches to "Fault State" by publishing a "Fault" message and triggers the algorithm in the downstream units. In radial feeders, based on the direction of the overcurrent sensed by the relays in SUs, the event location could be detected and reported to the SRUs.

The SU which senses the overcurrent in the backward direction (i.e., from downstream to upstream unit), changes its status to the "Backward Fault State" and publishes a "Found" message to the upstream SU. Subsequently, its status changes to the "Found State" to isolate the faulty segment of the feeder and publishes an "Isolated" message to the SRUs, announcing that the fault location is identified and the fault is successfully isolated. Once the SRUs receive the "Isolated" message, they start the SR process by switching to "Restore State". It must be noted that the publisher of the "Isolated" message is known to the SRUs, which assists to find out the location of the fault. By utilizing the pre-fault measurements received from all units in the feeder, the SRUs check the criterion in (13). If it is satisfied for an SRU and no other SRU in the faulty feeder has yet restored the loads, it closes its Tie- breaker and publishes an "Accomplished" message to other SRUs to terminate the SR process. The published "Accomplished" message by a particular SRU, subscribed by every other SRU, guarantees that only one SRU implements a restoration plan and the algorithm stops on other SRUs immediately. This action is followed by publishing "Dispatch", "Re-close", and "Re-connect" messages to be subscribed by the EVAUs, FBU, and DERUs of the faulty feeder, respectively, to complete the restoration process. These messages from the SRU would 
a) FBU

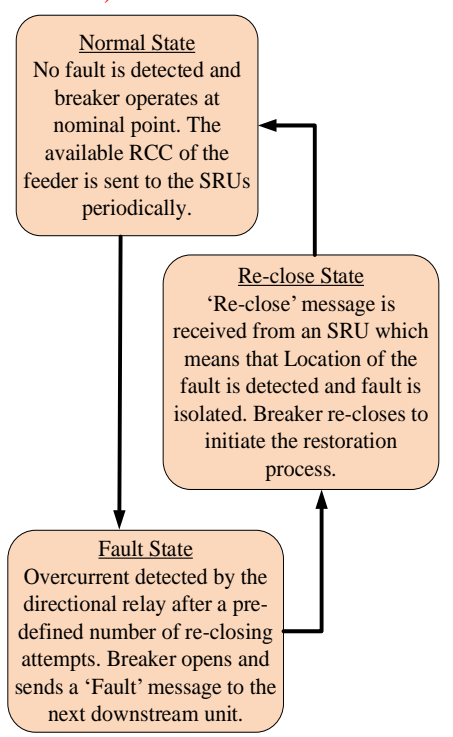

b) $\mathrm{SU}$

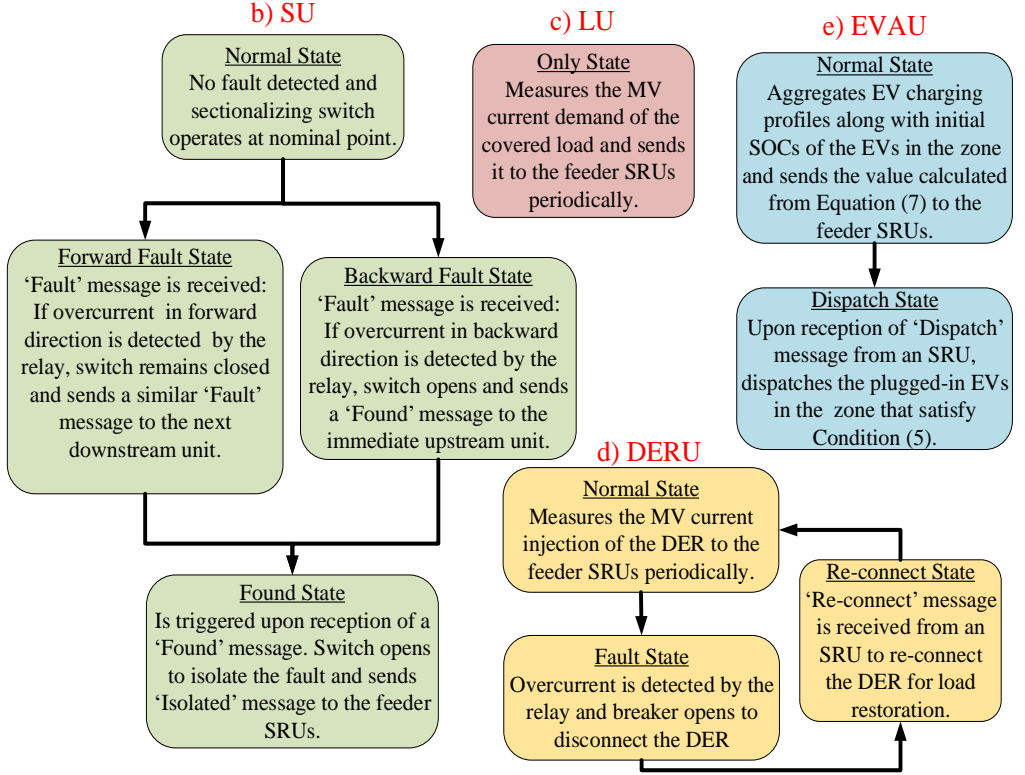

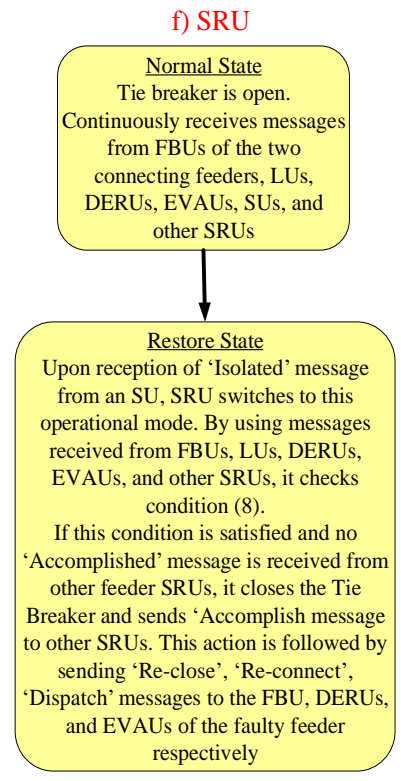

Fig. 2. Proposed operational states for a) FBUs, b) SUs, c) LUs, d) DERUs, e) EVAUs, and f) SRUs.
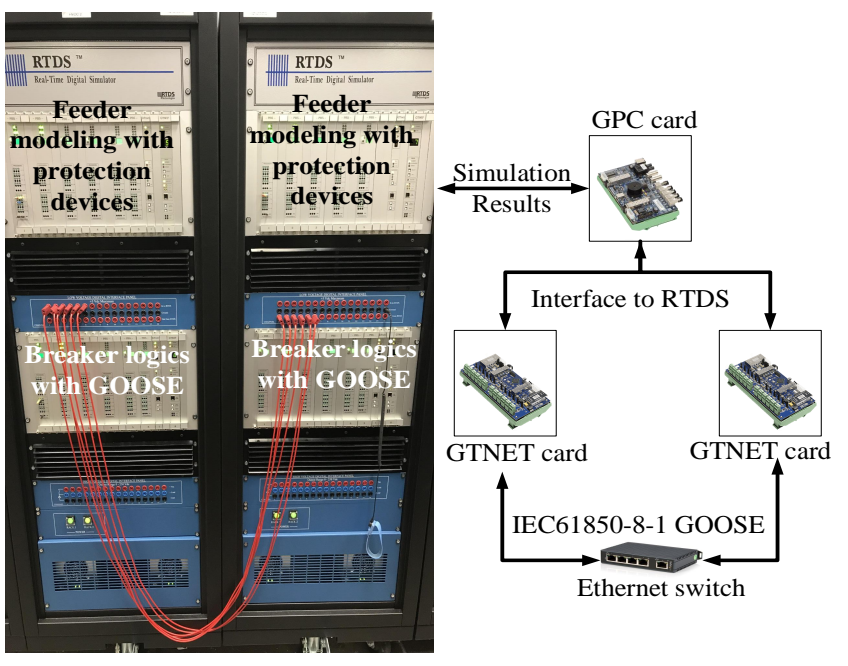

Fig. 3. Hardware-in-the-loop simulation platform using RTDS.

dispatch EVs, re-close the main feeder breaker, and re-connect DERs in the non-faulty segments of the feeder. Also, "Ready" message is published by this SRU after closing its Tie-breaker to be subscribed by all units and make them transit to "Normal State" and be prepared for the next emergency scenario.

The system performance, described in this section, relies heavily on functionality of the communication network and response time of the above-mentioned units (e.g. EV converters). Therefore, the performance of the designed system is significantly compromised under high latency or communication link failure scenarios. The system is designed to switch to the traditional SR mode, where no communication is required, if the Round Trip Time (RTT) of the messaging platform exceeds a pre-defined threshold. In other words, if the SRUs do not receive the input information from all parties listed in Table I within a certain range of time, the traditional SR based on the
TABLE I

Proposed Messages Exchanged Between the System OPERATIONAL UNITS

\begin{tabular}{llll}
\hline Message & Publisher & Subscriber & Type \\
\hline Fault & FBUs, SUs & adjacent downstream SU & Bool \\
Found & SUs & adjacent upstream SU & Bool \\
Isolated & SUs & SRUs & Bool \\
Dispatch & SRUs & EVAUs & Bool \\
Re-close & SRUs & FBUs & Bool \\
Re-connect & SRUs & DERUs & Bool \\
Accomplished & SRUs & SRUs & Bool \\
Ready & SRUs & All & Bool \\
\multirow{2}{*}{ Measurements } & LUs, FBUs, & SRUs & Float \\
& EVAUs, DERUs & & \\
\hline
\end{tabular}

information from the last energized counters and protection devices would react as a backup SR.

\section{HIL Testing Platform and System Parameters}

Real Time Digital Simulator (RTDS) with its specialized output boards, namely Giga-Transceiver Network Communication Card (GTNET), capable of publisher/subscriber IEC61850-8-1 GOOSE communication is utilized to verify the real-time performance of the proposed SR architecture. GTNET cards are configured to publish/subscribe GOOSE messages over an ideal gigabit Ethernet communication infrastructure with a delay less than $3 \mathrm{~ms}$. Each GTNET card could be a publisher and a subscriber at the same time and it interacts with the grid model via an interface board, called Gigabit Processing Card (GPC). IEC61850-8-1 GOOSE messaging, which is generally used to transmit the time-critical eventdriven information in the system [33], is adopted to exchange the messages proposed in Table I [33]. The Hardware-in-theLoop (HIL) platform setup is presented in Fig. 3 with more details available in [31]. The main advantage of this setup is the automated record-and-replay facility in the RTDS environment using scripting features for online system performance evaluation. The system parameters corresponding to the developed 
TABLE II

INFORMATION ON THE STUDIED GRID AND SimULATION PARAMETERS

\begin{tabular}{|c|c|c|}
\hline Bus no. & Connected Unit & Parameters \\
\hline 1 & FBU & Trans. $23 \mathrm{kV} / 15 \mathrm{kV}, 150 \mathrm{MVA}$ \\
\hline 2 & LU, SU & $\begin{array}{l}\mathrm{P}=63.1 \mathrm{~kW}, \mathrm{Q}=14.9 \mathrm{kVAR}, \text { cust.no }=19 \\
\mathrm{ZIP}=0.418,0.135,0.447\end{array}$ \\
\hline 3 & LU, SU & $\begin{array}{l}\mathrm{P}=42.3 \mathrm{~kW}, \mathrm{Q}=11.1 \mathrm{kVAR} \text {, cust.no=13 } \\
\mathrm{ZIP}=0.418,0.135,0.447\end{array}$ \\
\hline 4 & LU, SU & $\begin{array}{l}\mathrm{P}=140.2 \mathrm{~kW}, \mathrm{Q}=37.2 \mathrm{kVAR} \text {, cust } . \mathrm{no}=38 \\
\mathrm{ZIP}=0.418,0.135,0.447\end{array}$ \\
\hline 5 & DERU, LU, SU & $\begin{array}{l}\mathrm{P}=140.1 \mathrm{~kW}, \mathrm{Q}=7.4 \mathrm{kVAR}, \text { cust.no=41 } \\
\mathrm{ZIP}=0.418,0.135,0.447, \\
P_{D E R}^{\text {normal }}=5.1 \mathrm{~kW}, P_{D E R}^{\text {high }}=35.2 \mathrm{~kW}\end{array}$ \\
\hline 6 & EVAU1, LU, SU & $\begin{array}{l}\mathrm{P}=294.4 \mathrm{~kW}, \mathrm{Q}=74.5 \mathrm{kVAR}, \text { cust.no= }=87 \\
Z I P_{\text {Normal }}=0.413,0.138,0.449 \\
Z I P_{H \text { igh }}=0.402,0.143,0.455 \\
P_{\text {Normal }}^{E V A} \text { ject } \\
=45.3 \mathrm{~kW}\end{array}$ \\
\hline 7 & LU, SU & $\begin{array}{l}\mathrm{P}=140.3 \mathrm{~kW}, \mathrm{Q}=37.2 \mathrm{kVAR} \text {, cust. } \mathrm{no}=44 \\
\mathrm{ZIP}=0.418,0.135,0.447\end{array}$ \\
\hline 8 & EVAU2, LU, SU & $\begin{array}{l}\mathrm{P}=294.1 \mathrm{~kW}, \mathrm{Q}=71.1 \mathrm{kVAR}, \text { cust.no=102 } \\
Z I P_{\text {Normal }}=0.413,0.138,0.449, \\
Z I P_{\text {High }}=0.402,0.143,0.455, \\
P_{\text {NormalInject }}^{E V A}=26.4 \mathrm{~kW},\end{array}$ \\
\hline 9 & LU, SU & $\begin{array}{l}\mathrm{P}=63.6 \mathrm{~kW}, \mathrm{Q}=18.7 \mathrm{kVAR}, \text { cust.no }=20 \\
\mathrm{ZIP}=0.418,0.135,0.447\end{array}$ \\
\hline 10 & LU, SU & $\begin{array}{l}\mathrm{P}=84.6 \mathrm{~kW}, \mathrm{Q}=29.8 \mathrm{kVAR}, \text { cust.no }=26 \\
\mathrm{ZIP}=0.418,0.135,0.447\end{array}$ \\
\hline 11 & LU, SRUs & $\begin{array}{l}\mathrm{P}=31.5 \mathrm{~kW}, \mathrm{Q}=11.6 \mathrm{kVAR}, \text { cust } . \mathrm{no}=9 \\
\mathrm{ZIP}=0.418,0.135,0.447 \\
\alpha=0.9, \beta=\zeta=0.75\end{array}$ \\
\hline
\end{tabular}

modules in Fig. 1 along with the connection points of each proposed unit are reported in Table II. The load data and aggregated EV profiles have a 5-minute resolution, and data received by SRUs are updated every 15 minutes. Values reported in Table II are considered as the last updated information before the disruptive event (immediate pre-event measurements). The EV load profiles capture an aggregation of multiple EVs from various manufacturers, corresponding to EVs with the capacity up to $19.2 \mathrm{~kW}$ and $S o C_{\text {mobility }}^{\text {min }}=30 \%$, where additional information can be found in [32]. The constraints described in (5)-(13) are implemented through the built-in arithmetic modules, logic gates, and computational units in the RTDS environment. These arithmetic/computational modules, which are used to model the dispatched EVAUs, limit the output of the current source in such a way that constraints related to EV discharging-e.g., minimum energy left for mobility requirements in (10)—are satisfied.

\section{Test Case Scenarios and Evaluation Results}

\section{A. Evaluation Framework}

Resilience assessments in power systems are centered on HILP events where most of the standard reliability metrics (based on outage frequency/duration) are not able to adequately address and quantify the restoration resources [4].
There are multiple dimensions involved in power grid resilience assessment such as energy-based, time-based, and cost-based improvements [4]. Assessment in this paper focuses on feeder-level energy-based improvements, i.e., Feeder Resourcefulness (FR) and Restoration Rapidity (RR). All the available resources involved in the SR process could be classified as: (i) Internal Backups (IB) and (ii) External Backups (EB). IB refers to all resources within the faulty feeder which are employed to contribute to a swift restoration and, in this paper, include the DERs and EVs connected to the non-faulty segments of the faulty feeder. EBs are any other resources in the network located outside of the faulty feeder which can be connected to the faulty feeder only during the SR process and is, in this paper, the assisting capacity from external feeders. Based on this classification, the ratio of the utilized IB and EB resources could represent the feeder resourcefulness (FR). The RR of the system is evaluated by restoration Plan Steps and Interruptions (PSI). This is indicated by summation of the ratios between interruption duration of each load and the Total Time to Restoration $(T T R)$ in a faulty feeder. $T T R$ is the time interval from the moment an event occurs to that when its is entirely cleared. During the restoration process, different load interruption duration depends on the restoration algorithm and the number of steps taken to achieve a full restoration. This is reflected by multiplying the total number of steps taken for a full restoration (S) to the total interruption duration over $T T R$.

$$
F R=\left(\frac{I B^{T o t}}{I B^{T o t}+E B^{T o t}}\right), R R=\underbrace{\frac{1}{S \times\left(\sum_{i}^{S}\left(\frac{\Delta t_{i} \times n_{i}}{T T R}\right)\right)}}_{\text {Plan Steps and Interruptions (PSI) }}
$$

Figure 4 conceptually visualizes the sensitivity of the feederlevel resilience with regards to the FR and PSI. It could be perceived from this figure that the grid resilience has a direct and reverse relation with FR and PSI, respectively, while swinging between maximum and minimum limits.The restoration process proposed in this paper includes three main steps $(S=3)$, and the interruption durations $\left(\Delta t_{i}\right)$ are as follows: $\Delta t_{1}$ : time interval between opening and re-closing FBU; $\Delta t_{2}$ : time interval between opening FBU and closing SRUs; $\Delta t_{3}$ : time for human intervention to clear the fault and close the open SUs manually.

\section{B. Test Case Scenarios}

Figure 5 demonstrates details of the case scenarios which are tested and presented from the simplest to the most advanced one. In order to compare various feasible scenarios, a disastrous fault event is simulated at a fixed location between Bus 3 and Bus 4 (SU6 and SU7) in Feeder 1 and a given outage duration. The fault events can, however, occur at any time and location in the system. Pre-fault values of the system parameters, which are used by SRUs, are presented in Table II. In order to capture the entire behavior of the system from preevent to post-event operating state, values are taken in kA and zoomed several orders of magnitudes for better comparisons.

Case I: Original System (Base Scenario): 


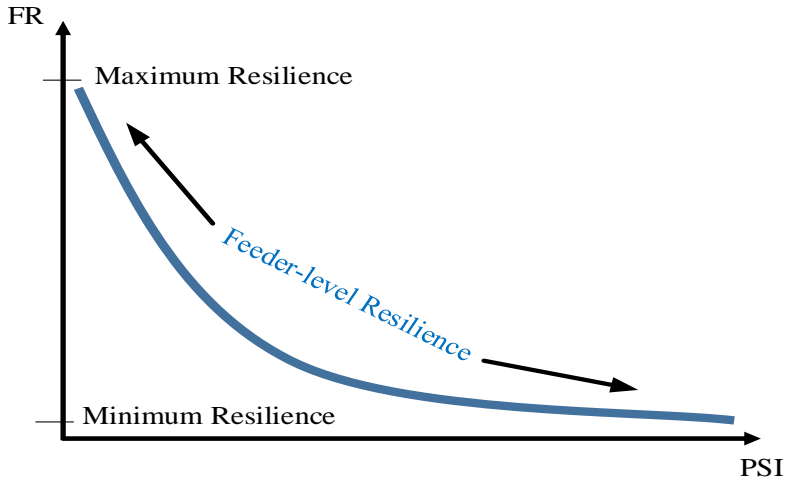

Fig. 4. Conceptual sensitivity of the feeder-level resilience with regards to FR and PSI.

TABLE III

SUMMARY OF THE RESULTS IN CASE I

\begin{tabular}{ccccc}
\hline $\begin{array}{c}\text { Total } \\
\text { restorable } \\
{[\mathrm{A}]}\end{array}$ & $\begin{array}{c}\text { FBU } \\
\text { covered } \\
{[\mathrm{A}]}\end{array}$ & $\begin{array}{c}\text { SRU } \\
\text { covered } \\
{[\mathrm{A}]}\end{array}$ & $\begin{array}{c}\text { RR } \\
\text { Inx. }\end{array}$ & $\begin{array}{c}\text { FR } \\
\text { Inx. } \\
\%\end{array}$ \\
\hline 59.96 & 7.73 & 52.23 & 0.75 & 12.89 \\
\hline
\end{tabular}

As the reference test case, the original system without DER units and EV aggregators is investigated in Case I. The faulty feeder is restored solely through imported power from an external feeder. The self-reconfiguration and real-time current flows of the critical units are displayed in Fig. 6, where different stages of the entire process including the pre-event, faulty, and restoration are highlighted. The first display in Fig. 6 illustrates the moment when each unit publishes its eventdriven GOOSE message (see Table I). It can be observed from curves in Fig. 6 that, once the event is activated, the feeder-level current captured by the FBU (red curve) reaches a peak and the protection units are triggered to operate and exchange messages to isolate the fault. The total load to be restored, restoration rapidity, and the load eventually restored by FBU and SRU are reported in Table III. Based on the event location between Buses 3 and 4 and the information on the number of customers connected to each Bus, 32 customers experience $\Delta t_{1}$ and 367 customers go through $\Delta t_{2}$. According to [21], 45 minutes is considered for $\Delta t_{3}$ in order to evaluate the restoration rapidity. Fewer number of units involved in the SR process leads to lower complexity of the restoration mechanism, lower number of messages exchanged between the units, and a lower computational burden, and hence, the units can react fast to contribute to the SR process. However, the tension on the external backup is high due to low utilization of internal backups and available resources.

\section{Case II: Original System with DERU:}

In this test case, DERU located in the non-faulty segment of the faulty feeder is involved in the restoration process in addition to the external backup. The first display in Fig. 7 demonstrates the self-reconfiguration actions based on the GOOSE messages along with the current flows in critical units. Color-coded curves in Fig. 7 illustrate the contribution of the DERU and the moment when it is re-connected for SR. Purple line represents the DERU contribution which makes the green
TABLE IV

SUMMARY OF THE RESULTS IN CASE II

\begin{tabular}{ccccccc}
\hline $\begin{array}{c}\text { Total } \\
\text { restorable } \\
{[\mathrm{A}]}\end{array}$ & $\begin{array}{c}\text { FBU } \\
\text { covered } \\
{[\mathrm{A}]}\end{array}$ & $\begin{array}{c}\text { SRU } \\
\text { covered } \\
{[\mathrm{A}]}\end{array}$ & $\begin{array}{c}\text { DERU } \\
\text { covered } \\
{[\mathrm{A}]}\end{array}$ & $\begin{array}{c}\text { RIP } \\
\%\end{array}$ & $\begin{array}{c}\text { RR } \\
\text { Inx. }\end{array}$ & $\begin{array}{c}\text { FR } \\
\text { Inx. } \\
\%\end{array}$ \\
\hline 59.62 & 7.56 & 50.59 & 1.473 & 3.13 & 0.67 & 15.15 \\
\hline
\end{tabular}

line (current flow in SRU representing imported power) remain at a lower level compared to Case I. The total restorable load along with contributions from FBU, SRU, DERU, and the Reduced Imported Power (RIP) are reported in Table IV. In order to highlight the DERs role and contribution in the SR, the high power injection rate of the DERU in Table II is employed in this test scenario. Due to the fixed fault location in all scenarios, the number of affected customers by each interruption duration $\left(\Delta t_{i}\right)$ is considered the same as that in Case I. The number of messages and the computational burden of SRUs increase in this case by taking DERU into account ( $\alpha$ and $\beta$ ), while the imported power is reduced by $3.13 \%$.

\section{Case III: Original System with DERU + EVAUs:}

This scenario aims at demonstrating the contributions of the internal backups to further improvement of the feederlevel resourcefulness and resilience through EVs in addition to the available resources considered in Case II. In the pre-event stage, the EVAUs publish the potential V2G capacity by the EVs in their zone based on the conditions described in Section II. Once the fault is detected and isolation is accomplished by responsible units, GOOSE messages are exchanged between SRUs and EVAUs to trigger utilizing the V2G capacity for restoration. The penetration rate of EVAUs and DERU are reported in Table II. The total power injection of the EVAUs is $85.2 \mathrm{~kW}$ with $75 \%$ availability, with the potential to increase with more prevalent deployment of EVs in the near future. Similar to the previous test cases, a summary of results are displayed in Table V. The colored curves in Fig. 8 highlight the joint contribution of EVAUs and DERU in the SR. The safety margin via $\alpha, \beta$ and $\zeta$ in Table II accounts for the uncertainties in the injected power by V2G capacity (due to drivers' behavior) and DER units. Hence, the restoration does not heavily rely on DERU and the EVAUs. The main advantage of employing such auxiliary internal backups is to reduce the stress on the external feeder through local resources. The most magnified display on the green line, which represents the EBs, shows the contribution of EBs in this case compared to previous scenarios. The number of published GOOSE messages and SR computational burden in this case has increased. However, higher penetration of EVAUs and DERU results in a drastic reduction in the imported power from the external backup. Specifically, the imported power in this scenario has reduced by $10.59 \%$ compared to the base case condition which highlights a higher cost-effective feeder-level resilience in the post-contingency interval.

\section{Case IV: Subsequent Events (Multiple Faults):}

This test case extends the previous Case III to showcase the functionality of the designed resilience-focused load restoration in response to extreme events with subsequent impacts 


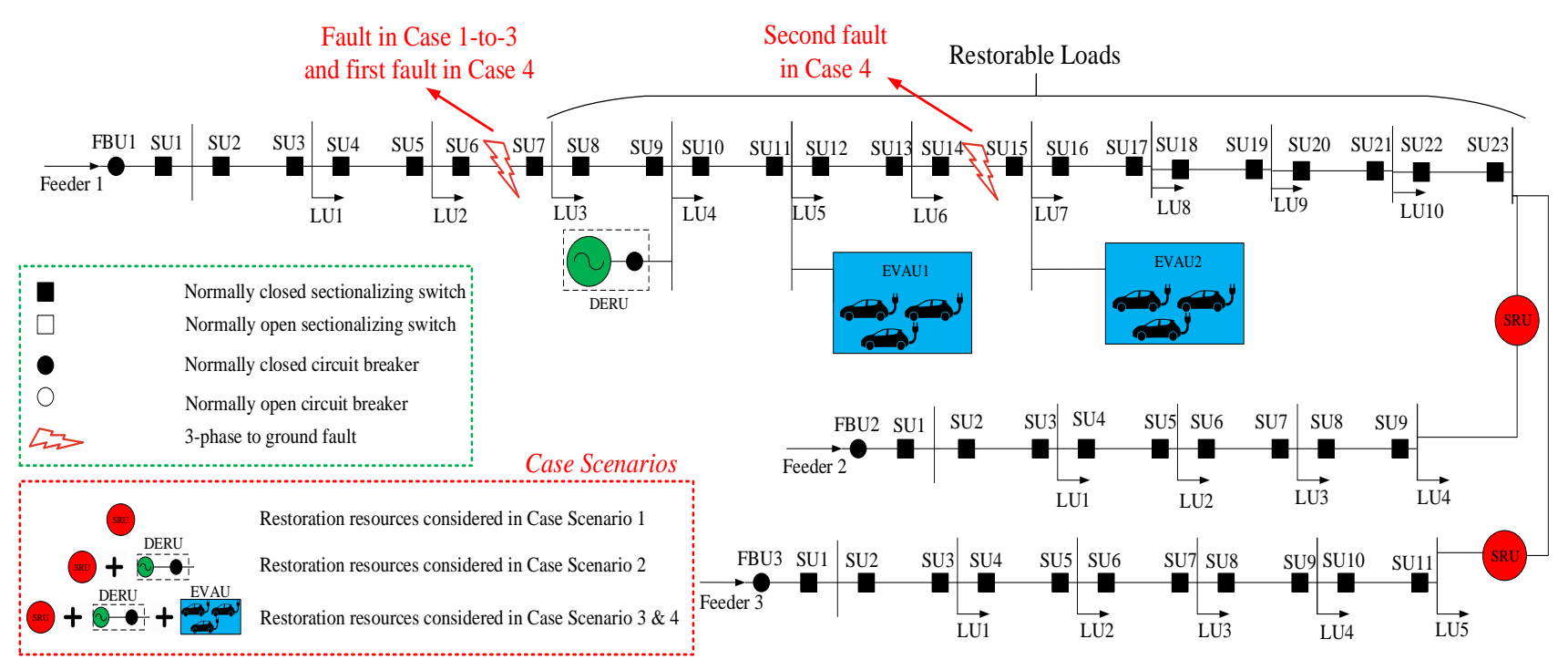

Fig. 5. Detailed demonstration of the grid under test related to Table II along with the case scenarios.

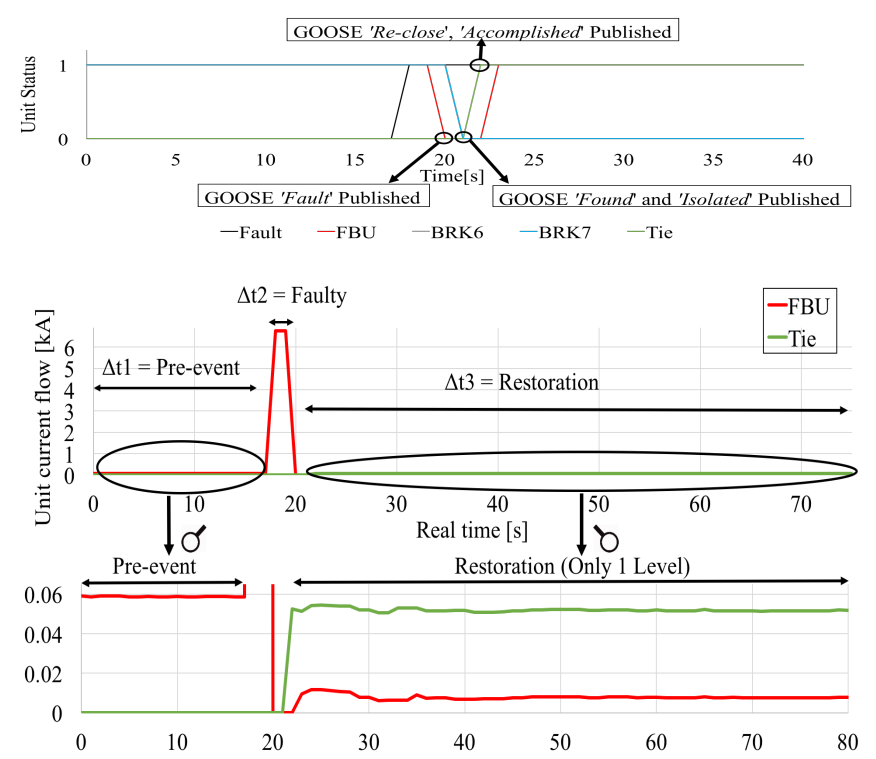

Fig. 6. HIL results for operational units in Case I.

on the grid (e.g. cascading failure or multiple faults). Critical moments are marked in the first display of Fig. 9 from $t_{1}$ to $t_{17}$. The first fault occurs at $t_{1}$ and the corresponding $\mathrm{SR}$ process is accomplished at $t_{9}$ through the procedure described in Case III. A GOOSE message named "Ready" has been published by the SRU after the first restoration and subscribed by all non-faulty units to be switched back to the normal operating state (pre- fault state). This ensures the system preparedness for the next fault. At $t_{10}$, the next fault occurs located between SU14 and SU15 (see Fig. 5) while the first fault is not yet fully cleared. This could be followed in the second display in Fig. 9, where there are two over-currents detected. Once the second fault occurs, the proposed SR solution, which runs in the external feeder connected temporarily to the main faulty feeder after the first

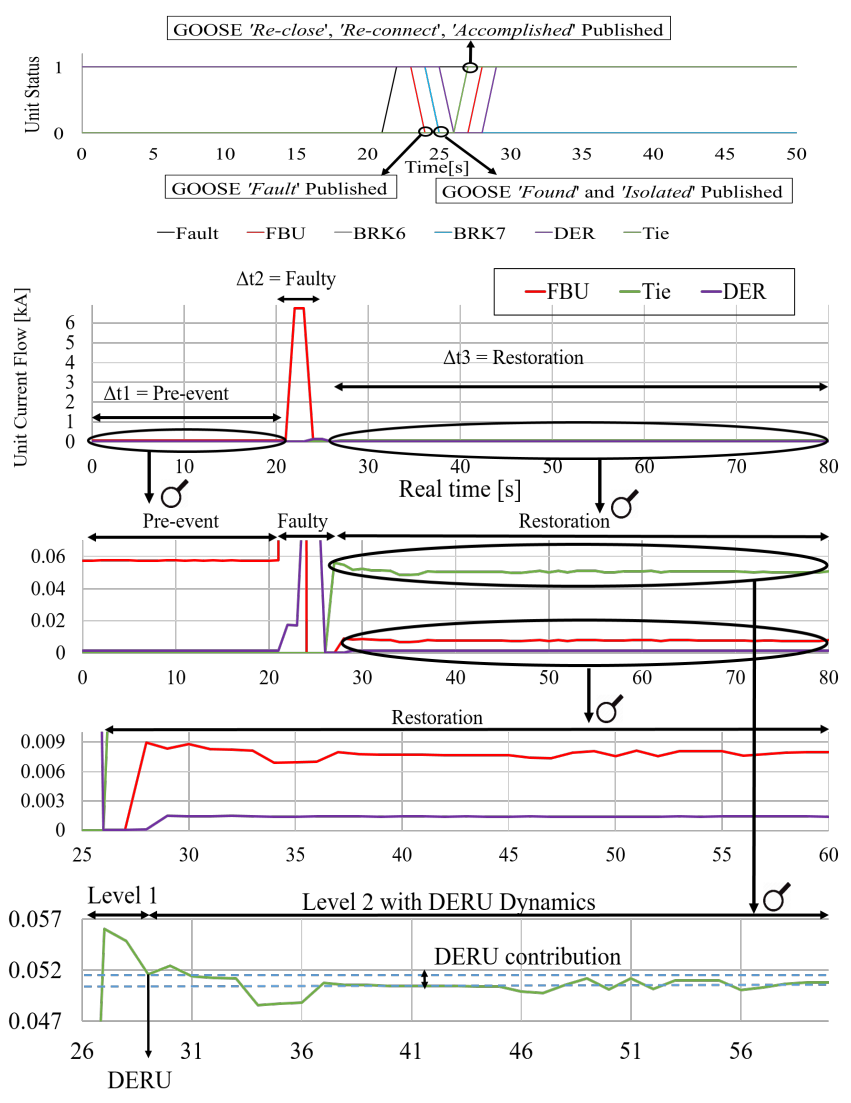

Fig. 7. HIL results for operational units in Case II

fault, initiates a self-reconfiguration action by opening FBU2, SU14, and SU15 to isolate the fault. Also, EVAUs and DERUs are isolated by the corresponding reconfiguration action. Once the second fault is isolated, the FBU2 in the external feeder recloses to restore the non-faulty loads in the external feeder and SRU dispatches the local generations and the EVAUs 


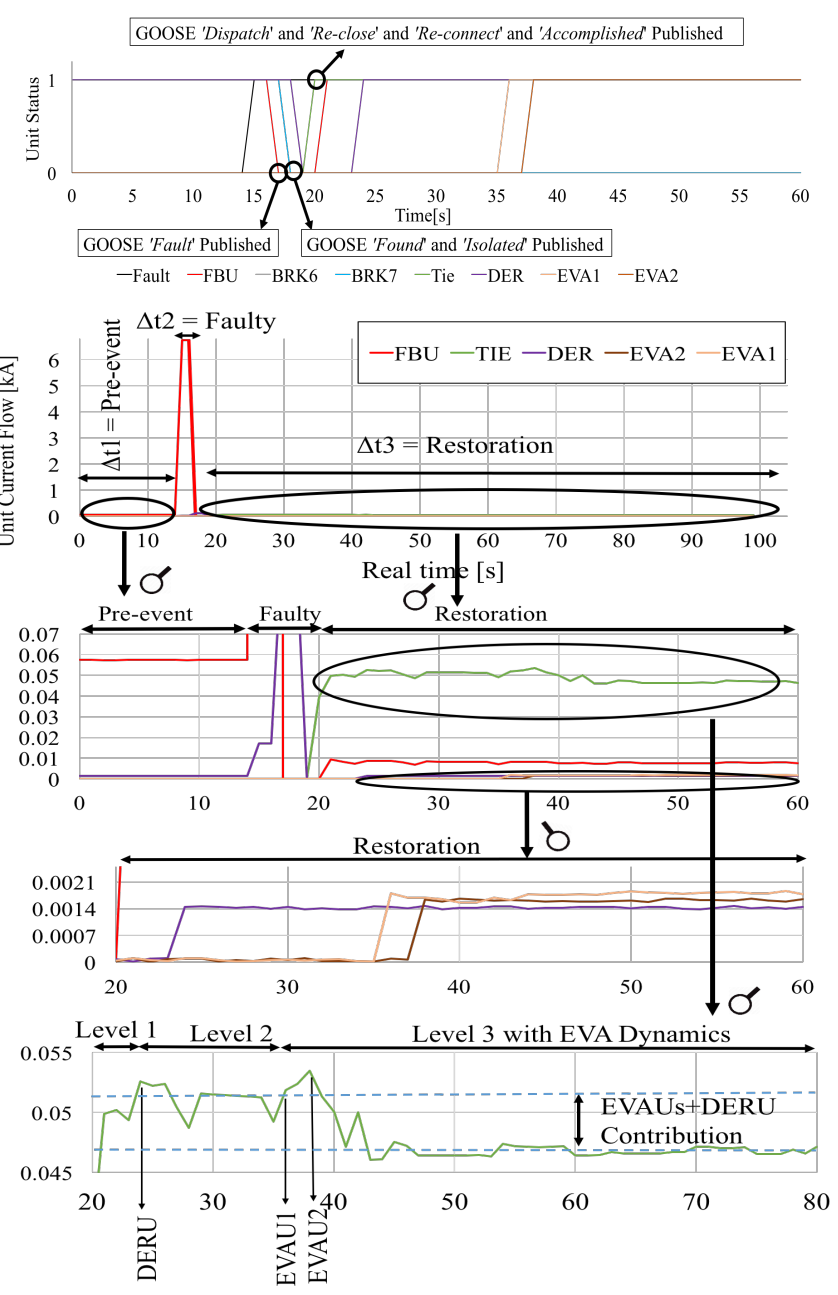

Fig. 8. HIL results for operational units in Case III

TABLE V

SUMMARY OF THE RESULTS IN CASE III

\begin{tabular}{cccccccc}
\hline $\begin{array}{c}\text { Total } \\
\text { restorable } \\
{[\mathrm{A}]}\end{array}$ & $\begin{array}{c}\text { FBU } \\
\text { covered } \\
{[\mathrm{A}]}\end{array}$ & $\begin{array}{c}\text { SRU } \\
\text { covered } \\
{[\mathrm{A}]}\end{array}$ & $\begin{array}{c}\text { DERU } \\
\text { covered } \\
{[\mathrm{A}]}\end{array}$ & $\begin{array}{c}\text { EVAUs } \\
\text { covered } \\
{[\mathrm{A}]}\end{array}$ & $\begin{array}{c}\text { RIP } \\
\text { Inx. } \\
\%\end{array}$ & $\begin{array}{c}\text { RR } \\
\text { Inx. }\end{array}$ & $\begin{array}{c}\text { FR } \\
\text { Inx. } \\
\%\end{array}$ \\
\hline 59.50 & 7.94 & 46.70 & 1.40 & 3.46 & 10.59 & 0.57 & 21.39 \\
\hline
\end{tabular}

located in the non-faulty areas. Considering the location of the first fault (between Bus 3 and Bus 4) and the second fault (between Bus 7 and Bus 8), only EVAU2, located at Bus 8 (non-faulty segment and energized by FBU2), re-dispatches for restoration of the second fault (EVAU1 and DERU remain isolated). This behavior is observed in the most bottom display in Fig. 9, where the contribution of EVAU2 is magnified. Sequence of events in real time along with the load restoration achievements are reported in Table VI and Fig. 9. At $t_{17}$, the "Ready" GOOSE message is published again to make the system prepared for the next possible faults.

\section{Summary and Discussion}

Among all dimensions (energy, cost, and time) involved in resilience improvement, this paper focused on energy restoration and feeder-level resilience improvements. Test Cases I to III demonstrated that more investments on peer-to-peer
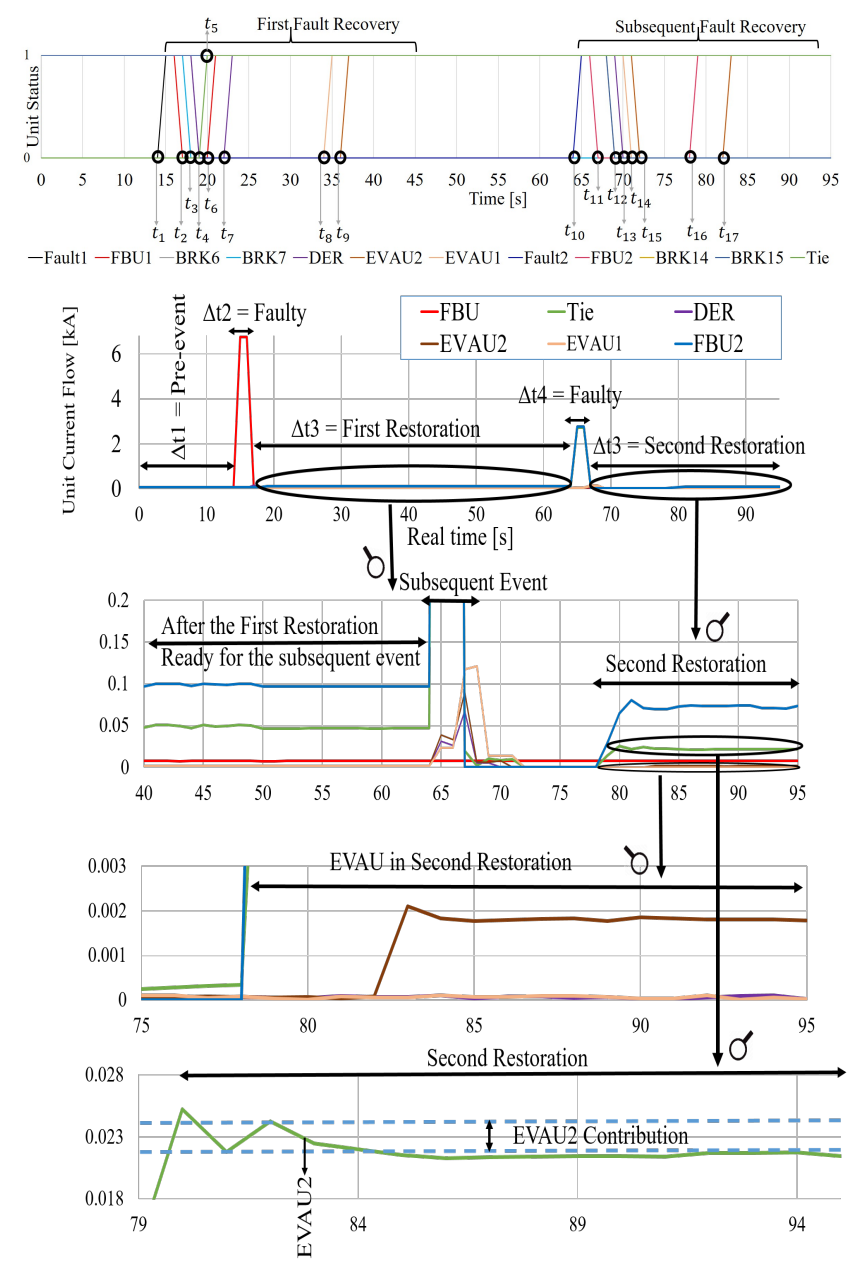

Fig. 9. HIL results for operational units in Case IV.

communications in distribution grids enable implementation of advanced SR algorithms that are able to best utilize the feeder-level internal backups. Consequently, with a relatively faster restoration process, resourcefulness and resilience in the system will be enhanced. While the restoration rapidity of all scenarios are similar, Case I, with the simplest SR mechanism and the lowest number of published GOOSE messages, has the highest restorative rapidity but the lowest feeder-level resourcefulness during the post-contingency operating state. By utilizing the DERU in Case II and a joint DERU and EVAUs in Case III, deployment of available external backups is statistically presented in Table VII. Figure 10 provides a comparison overview of the real-time utilization of EBs in the studied test case scenarios. The lowest EB utilization belongs to Case 3 (blue curve) and the red curve sits on top of others, representing the EB utilization in Case 1. The higher utilization of the modern grid services results in a heightened feeder-level resilience when tested on the same event in all test case scenarios.

Case IV is designed to highlight the functionality of the proposed SR architecture to best respond to extreme HILP scenarios with multiple faults in a feeder in presence of DERs and EV aggregators. With increased number of EVs in the near future, the numerical results in this paper proved the efficacy of the V2G technologies as a modern auxiliary SR resource to 
TABLE VI

Sequence of Events Related to the Top Curve in Fig. 7

\begin{tabular}{|c|c|c|c|c|c|}
\hline$t_{1}$ & $t_{2}$ & $t_{3}$ & $t_{4}$ & $t_{5}$ & $t_{6}$ \\
\hline $\begin{array}{c}\text { First } \\
\text { fault } \\
\text { occurs, } \\
59.5[\mathrm{~A}] \\
\text { to be } \\
\text { restored }\end{array}$ & $\begin{array}{l}\text { 'Fault' } \\
\text { GOOSE } \\
\text { published }\end{array}$ & $\begin{array}{l}\text { 'Found' } \\
\text { 'Isolated' } \\
\text { GOOSEs } \\
\text { published }\end{array}$ & $\begin{array}{l}\text { Restoration } \\
\text { triggered } \\
\text { SRU closes } \\
46.70[\mathrm{~A}] \\
\text { restored }\end{array}$ & $\begin{array}{c}\text { 'Dispatch', } \\
\text { 'Re-close', } \\
\text { 'Re-connect', } \\
\text { 'Accomplished' } \\
\text { 'Ready' } \\
\text { GOOSEs } \\
\text { published }\end{array}$ & $\begin{array}{c}\text { FBU1 } \\
\text { recloses } \\
7.94[\mathrm{~A}] \\
\text { restored }\end{array}$ \\
\hline$t_{7}$ & $t_{8}$ & $t_{9}$ & $t_{10}$ & $t_{11}$ & $t_{12}$ \\
\hline $\begin{array}{c}\text { DERU } \\
\text { reconnects } \\
1.94[\mathrm{~A}] \\
\text { restored }\end{array}$ & $\begin{array}{c}\text { EVAU1 } \\
\text { dispatches } \\
1.81[\mathrm{~A}] \\
\text { restored }\end{array}$ & $\begin{array}{c}\text { EVAU2 } \\
\text { dispatches } \\
1.65[\mathrm{~A}] \\
\text { restored }\end{array}$ & $\begin{array}{l}\text { Second } \\
\text { fault } \\
\text { occurs }\end{array}$ & $\begin{array}{c}\text { 'Fault' } \\
\text { GOOSE } \\
\text { published }\end{array}$ & $\begin{array}{l}\text { 'Found' } \\
\text { 'Isolated' } \\
\text { GOOSEs } \\
\text { published }\end{array}$ \\
\hline$t_{13}$ & $t_{14}$ & $t_{15}$ & $t_{16}$ & $t_{17}$ & $t \geqslant t_{17}$ \\
\hline $\begin{array}{c}\text { Restoration } \\
\text { triggered }\end{array}$ & $\begin{array}{l}\text { EVAU1 } \\
\text { isolated } \\
\text { 'Re-close' } \\
\text { 'Dispatch' } \\
\text { GOOSEs } \\
\text { published }\end{array}$ & $\begin{array}{l}\text { EVAU2 } \\
\text { isolated }\end{array}$ & $\begin{array}{c}\text { FBU2 } \\
\text { recloses } \\
21.16[\mathrm{~A}] \\
\text { restored }\end{array}$ & $\begin{array}{c}\text { EVAU2 } \\
\text { dispatches } \\
1.77[\mathrm{~A}] \\
\text { restored } \\
\text { 'Ready'GOOSE } \\
\text { Published }\end{array}$ & $\begin{array}{l}\text { Ready } \\
\text { for the } \\
\text { next } \\
\text { fault }\end{array}$ \\
\hline
\end{tabular}

TABLE VII

COMParison OF THE Test CASE SCEnARIos

\begin{tabular}{ccccc}
\hline Case no. & $\begin{array}{c}\text { Internal Backup } \\
(\text { FR) }\end{array}$ & $\begin{array}{c}\text { External Backup } \\
{[\%]}\end{array}$ & $\begin{array}{c}\text { RR } \\
\text { Index }\end{array}$ & $\begin{array}{c}\text { RIP } \\
{[\%]}\end{array}$ \\
& {$[\%]$} & & & \\
\hline 1 & 12.89 & 87.10 & 0.75 & N/A \\
2 & 15.15 & 84.84 & 0.67 & 3.13 \\
3 & 18.27 & 81.72 & 0.57 & 10.59 \\
\hline
\end{tabular}

improve the feeder-level resourcefulness during HILP events.

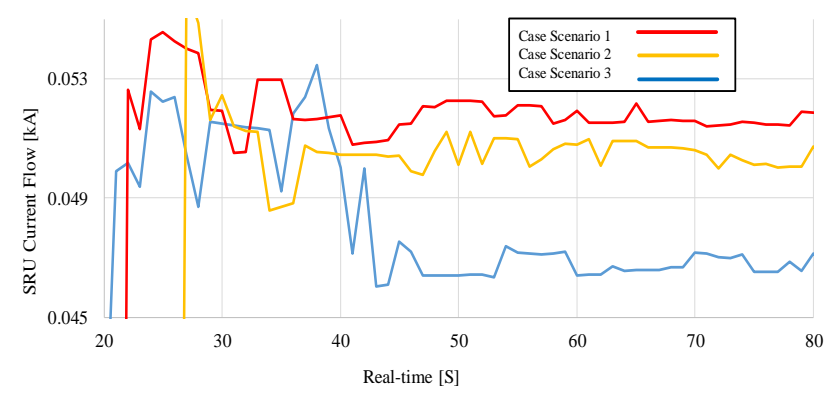

Fig. 10. Real-time HIL results for comparison of the current flow in SRU unit, EB utilization, in different case scenarios.

\section{CONCLUSION}

In this paper, a resilient service restoration architecture was designed utilizing the IEC 61850-8-1 GOOSE communication principles. Unlike the past studies, the proposed solution harnesses (a) the imported power and flexibility from the neighboring networks, (b) Distributed Energy Resources (DERs), and (c) aggregated vehicle to grid (V2G) capacity in all steps of restoration when facing an extreme HILP incident with multiple faults. The proposed real-time SR mechanism was implemented using the RTDS HIL platform and the contribution of each SR resource was numerically quantified by a developed resilience evaluation framework. The proposed solution ensures an enhanced feeder-level resourcefulness that can contribute to agile response and efficient recovery. This is primarily achieved by a strategic deployment of major modern resources (with focus on EVs contribution) during a sequence of multiple faults. Four test case scenarios were tested and presented, through which a $10.59 \%$ stress reduction on external SR resources compared to the base case condition was realized.

\section{REFERENCES}

[1] M. Panteli and P. Mancarella, "The grid: Stronger, bigger, smarter?: Presenting a conceptual framework of power system resilience," IEEE Power and Energy Magazine, vol. 13, no. 3, pp. 58-66, 2015.

[2] C. Wang, Y. Hou, F. Qiu, S. Lei, and K. Liu, "Resilience enhancement with sequentially proactive operation strategies," IEEE Transactions on Power Systems, vol. 32, no. 4, pp. 2847-2857, 2017.

[3] P. Dehghanian, "Power system topology control for enhanced resilience of smart electricity grids," Ph.D. Dissertation, 2017.

[4] P. Bajpai, S. Chanda, and A. K. Srivastava, "A novel metric to quantify and enable resilient distribution system using graph theory and choquet integral," IEEE Transactions on Smart Grid, 2016.

[5] H. Farzin, M. Fotuhi-Firuzabad, and M. Moeini-Aghtaie, "Enhancing power system resilience through hierarchical outage management in multi-microgrids," IEEE Transactions on Smart Grid, vol. 7, no. 6, pp. 2869-2879, 2016.

[6] Z. Li and M. Shahidehpour, "Security-constrained unit commitment for simultaneous clearing of energy and ancillary services markets," IEEE transactions on power systems, vol. 20, no. 2, pp. 1079-1088, 2005.

[7] W. Ling, D. Liu, Y. Lu, P. Du, and F. Pan, "IEC 61850 model expansion toward distributed fault localization, isolation, and supply restoration," IEEE Transactions on Power Delivery, vol. 29, no. 3, pp. 977-984, 2014.

[8] M. Manbachi, A. Sadu, H. Farhangi, A. Monti, A. Palizban, F. Ponci, and S. Arzanpour, "Impact of EV penetration on volt-var optimization of distribution networks using real-time co-simulation monitoring platform," Applied Energy, vol. 169, pp. 28-39, 2016.

[9] Y. Xu, C.-C. Liu, K. Schneider, F. Tuffner, and D. Ton, "Microgrids for service restoration to critical load in a resilient distribution system," IEEE Transactions on Smart Grid, 2016.

[10] V. Kumar, I. Gupta, and H. O. Gupta, "DG integrated approach for service restoration under cold load pickup," IEEE Transactions on power delivery, vol. 25, no. 1, pp. 398-406, 2010.

[11] Y.-L. Ke, "Distribution feeder reconfiguration for load balancing and service restoration by using G-nets inference mechanism," IEEE Transactions on Power Delivery, vol. 19, no. 3, pp. 1426-1433, 2004.

[12] M. AlOwaifeer, M. AlMuhaini, and A. AlSaggaf, "The impact of load management and renewable DG on the service restoration of future power distribution systems," in Environment and Electrical Engineering (EEEIC), 2015 IEEE 15th International Conference on, pp. 1789-1794, IEEE, 2015.

[13] A. Gholami, F. Aminifar, and M. Shahidehpour, "Front lines against the darkness: Enhancing the resilience of the electricity grid through microgrid facilities," IEEE Electrification Magazine, vol. 4, no. 1, pp. 18-24, 2016.

[14] X. Liu, M. Shahidehpour, Z. Li, X. Liu, Y. Cao, and Z. Bie, "Microgrids for enhancing the power grid resilience in extreme conditions," IEEE Transactions on Smart Grid, vol. 8, no. 2, pp. 589-597, 2017.

[15] B. Zhang, P. Dehghanian, and M. Kezunovic, "Optimal allocation of pv generation and battery storage for enhanced resilience," IEEE Transactions on Smart Grid, 2017.

[16] H. Hosseinirad and M. R. Haghifam, "An agent-based control system for outage management in distribution network in presence of distributed generation," 2012.

[17] P. Jamborsalamati, A. Sadu, F. Ponci, and A. Monti, "Implementation of an agent based distributed FLISR algorithm using IEC 61850 in active distribution grids," in Renewable Energy Research and Applications (ICRERA), 2015 International Conference on, pp. 606-611, IEEE, 2015.

[18] T. Zheng and H. Jia, "Application of multi-agent and impedance-based algorithm for fault location in power distribution systems with DG," in Advanced Power System Automation and Protection (APAP), 2011 International Conference on, vol. 2, pp. 1044-1049, IEEE, 2011.

[19] A. Farraj, E. Hammad, and D. Kundur, "A storage-based multiagent regulation framework for smart grid resilience," IEEE Transactions on Industrial Informatics, vol. 14, no. 9, pp. 3859-3869, 2018. 
[20] P. Parikh, I. Voloh, and M. Mahony, "Fault location, isolation, and service restoration (FLISR) technique using IEC 61850 GOOSE," in Power and Energy Society General Meeting (PES), 2013 IEEE, pp. 16, IEEE, 2013.

[21] P. Jamborsalamati, A. Sadu, F. Ponci, and A. Monti, "Design, implementation and real-time testing of an IEC 61850 based FLISR algorithm for smart distribution grids," in Applied Measurements for Power Systems (AMPS), 2015 IEEE International Workshop on, pp. 114-119, IEEE, 2015.

[22] A. Ahmadi, A. Tavakoli, P. Jamborsalamati, N. Rezaei, M. R. Miveh, F. H. Gandoman, A. Heidari, and A. E. Nezhad, "Power quality improvement in smart grids using electric vehicles: a review," IET Electrical Systems in Transportation, 2019.

[23] J. A. P. Lopes, F. J. Soares, and P. M. R. Almeida, "Integration of electric vehicles in the electric power system," Proceedings of the IEEE, vol. 99, no. 1, pp. 168-183, 2011.

[24] K. Knezović, S. Martinenas, P. B. Andersen, A. Zecchino, and M. Marinelli, "Enhancing the role of electric vehicles in the power grid: field validation of multiple ancillary services," IEEE Transactions on Transportation Electrification, vol. 3, no. 1, pp. 201-209, 2017.

[25] N. Xu and C. Chung, "Reliability evaluation of distribution systems including vehicle-to-home and vehicle-to-grid," IEEE Transactions on Power Systems, vol. 31, no. 1, pp. 759-768, 2016.

[26] W. Kempton and J. Tomić, "Vehicle-to-grid power implementation: From stabilizing the grid to supporting large-scale renewable energy," Journal of power sources, vol. 144, no. 1, pp. 280-294, 2005.

[27] K. Clement-Nyns, E. Haesen, and J. Driesen, "The impact of vehicle-togrid on the distribution grid," Electric Power Systems Research, vol. 81, no. 1, pp. 185-192, 2011.

[28] M. Yilmaz and P. T. Krein, "Review of the impact of vehicle-togrid technologies on distribution systems and utility interfaces," IEEE Transactions on power electronics, vol. 28, no. 12, pp. 5673-5689, 2013.

[29] M. Shaaban, M. Ahmed, T. EL-Fouly, and M. Salama, "Impact of integrating PEV and renewable sources on power system reliability assessment," in Electric Power and Energy Conversion Systems (EPECS), 2015 4th International Conference on, pp. 1-6, IEEE, 2015.

[30] H. Farzin, M. Fotuhi-Firuzabad, and M. Moeini-Aghtaie, "Reliability studies of modern distribution systems integrated with renewable generation and parking lots," IEEE Transactions on Sustainable Energy, vol. 8, no. 1, pp. 431-440, 2017.

[31] P. Jamborsalamati, A. Sadu, F. Ponci, and A. Monti, "A flexible HiL testing platform for performance evaluation of IEC 61850-based protection schemes," in Power and Energy Society General Meeting (PESGM), 2016, pp. 1-5, IEEE, 2016.

[32] M. Manbachi, H. Farhangi, A. Palizban, and S. Arzanpour, "A novel volt-var optimization engine for smart distribution networks utilizing vehicle to grid dispatch," International Journal of Electrical Power \& Energy Systems, vol. 74, pp. 238-251, 2016.

[33] F. Costa, A. Monti, F. Lopes, K. Silva, P. Jamborsalamati, and A. Sadu, "Two-terminal traveling-wave-based transmission-line protection," IEEE Transactions on Power Delivery, vol. 32, no. 3, pp. 1382-1393, 2017.

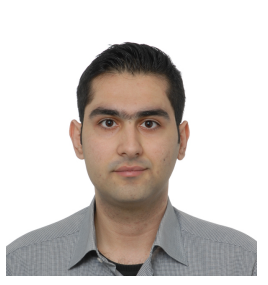

Pouya Jamborsalamati (S'14) received the B.Sc. degree from the University of Tehran, Tehran, Iran, in 2013, and the M.Sc. degree from RWTH-Aachen University, Aachen, Germany, in 2016, both in electrical engineering. He was with the ABB Corporate Research Center, Ratingen, Germany, in 2016. He is currently working toward the Ph.D. degree at Macquarie University, Sydney, NSW, Australia, with interests in power system reliability and resilience, power system operation and planning, and smart grids.

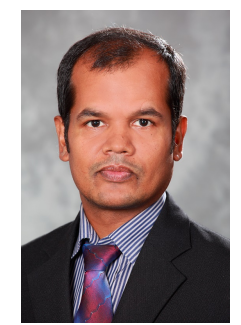

M. Jahangir Hossain (M'10, SM'13) received the $\mathrm{Ph} . \mathrm{D}$. degree from the University of New South Wales, Sydney, Australia, in electrical and electronic engineering. He is currently an Associate Professor with the Department of Engineering, Macquarie University. Before joining there, he served as a Senior Lecture and a Lecturer in the Griffith School of Engineering, Griffith University, for five years and as a Research Fellow in the School of Information Technology and Electrical Engineering, University of Queensland, Brisbane, Australia. His research interests include renewable energy integration and stabilization, voltage stability, micro grids and smart grids, robust control, electric vehicles, flexible ac transmission systems devices, and energy storage systems.

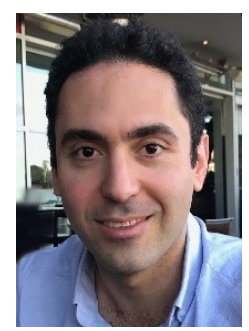

Seyedfoad Taghizadeh received his M.Sc. degree in Electrical and Electronic Engineering from the Universiti Tenaga Nasional (UNITEN), Malaysia, in 2013. He received the Ph.D. degree in Electrical Engineering from the Macquarie University, Australia in 2018. He is currently working as a Research Fellow in the School of Engineering, Macquarie University, Australia. His research interests include electric vehicle chargers, control systems, renewable energy integration, power quality, and energy storage systems.

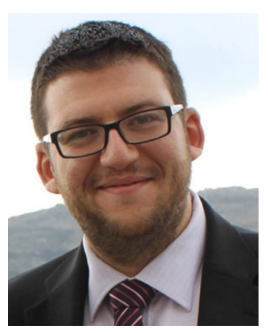

Georgios Konstantinou (S'08, M'11, SM'18) received the B.Eng. degree in electrical and computer engineering from the Aristotle University of Thessaloniki, Thessaloniki, Greece, in 2007, and the $\mathrm{Ph} . \mathrm{D}$. degree in electrical engineering from The University of New South Wales (UNSW), Sydney, Australia, in 2012. From 2012 to 2015, he was a Research Associate with UNSW. He is currently a Lecturer with the School of Electrical Engineering and Telecommunications, UNSW and an Australian Research Council Early Career Research Fellow. His main research interests include hybrid and modular multilevel converters, power electronics for $\mathrm{HVdc}$ and energy storage applications, pulsewidth modulation, and selective harmonic elimination techniques for power electronics. Dr. Konstantinou is an Associate Editor of IEEE TRANSACTIONS ON POWER ELECTRONICS and IET Power Electronics.

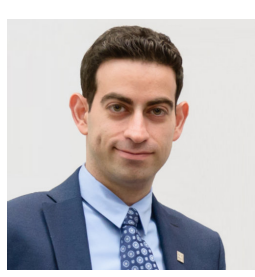

Moein Manbachi (GS'09) received the Ph.D. degree in applied sciences from Simon Fraser University, BC, Canada, in 2015. Since 2011, he has been a Research Assistant and from 2014 to 2015, an Assistant Instructor with the British Columbia Institute of Technology, Burnaby, BC, Canada. He is currently a Post-Doctoral Fellow with the Department of Electrical and Computer Engineering, University of British Columbia, Vancouver, Canada. His current research interests include smart grids, power system optimization, distributed generation, renewable energies, cogeneration systems, and energy conversion and management.

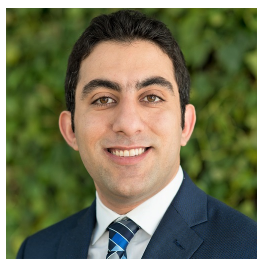

Payman Dehghanian (S'11, M'17) is an Assistant Professor at the Department of Electrical and Computer Engineering in George Washington University, Washington, D.C., USA. He received the B.Sc., M.Sc., and Ph.D. degrees all in Electrical Engineering respectively from University of Tehran, Tehran, Iran, in 2009, Sharif University of Technology, Tehran, Iran, in 2011, and Texas AM University, Texas, USA in 2017. His research interests include power system protection and control, power system reliability and resiliency, asset management, and smart electricity grid applications. Dr. Dehghanian is the recipient of the 2013 IEEE Iran Section Best M.Sc. Thesis Award in Electrical Engineering, the 2014 and 2015 IEEE Region 5 Outstanding Professional Achievement Awards, and the 2015 IEEE-HKN Outstanding Young Professional Award. 